Maha Авu Hatoum

ORCID 0000-0001-5720-8214

Jaffa Middle School, Izrael

\title{
ONLINE COLLABORATIVE DISCOURSE AS A FORM OF SUPPORT FOR STUDENTS WITH LEARNING DIFFICULTIES IN MATHEMATICS
}

\begin{abstract}
AвSTRACt. Hatoum Maha Abu, Online Collaborative Discourse as a Form of Support for Students with Learning Difficulties in Mathematics [Online Collaborative Discourse jako forma wsparcia uczniów z trudnościami w uczeniu się matematyki]. Studia Edukacyjne nr 57, 2020, Poznań 2020, pp. 301-319. Adam Mickiewicz University Press. ISSN 1233-6688. DOI: 10.14746/se.2020.57.21
\end{abstract}

The present research study was carried out in an online learning environment in a small group of eighth-grade students. The research proposes a learning framework that relies on collaborative mathematical discourse with the intention to promote the reasoning ability of students with difficulties in mathematics. The aim of mathematical discourse is the reciprocal building of the ability of the learner with difficulties to provide explanations during the discourse between the learner and his peers and between the learner and the teacher. This type of learning was found to be effective, and the communicational continuum between the learner and the material and between the learner and the group is preserved. The learning process built on authentic mathematical tasks strengthened the learners' ability to create communication among themselves. The discourse encouraged the development of mathematical thinking abilities among the learners with difficulties, such as posing arguments and drawing conclusions while explaining and justifying these arguments. The mathematical discourse also encouraged students to choose and to monitor the form and processes of their thinking and increased their problem-solving ability.

Key words: online learning, online collaborative discourse, mathematical reasoning, difficulties in learning mathematics, students with learning difficulties

\section{Introduction}

The mathematical thinking as a process constitutes a very complicated activity. ${ }^{1}$ With the deployment of the New Horizon Reform, the individualized

${ }^{1}$ J. Mason, L. Burton, K. Stacey, Thinking Mathematically, Inggris: Pearson Education Limited 2010; K. Stacey, What Is Mathematical Thinking and Why Is It Important? Paper Presented in APEC Symposium: Innovative Teaching Mathematics through Lesson Study II, 2006 December, 3-4. 
hour was added to the schools. The individualized hour is an hour in which there is teaching in small groups, no more than five students, ${ }^{2}$ with the goal of responding to the learners' needs in a personal manner. ${ }^{3}$ The main difference between the learners is expressed in achievements, in mental abilities, in abilities to pay attention and concentrate, in the background, and in the diverse learning styles. ${ }^{4}$ The learning in small groups ensures quality learning, which is active, collaborative, and equal. ${ }^{5}$

Reasoning, problem solving, and making connections between ideas ${ }^{6}$ are some of the abilities of mathematical thinking that the learner is required to develop during his learning. Teaching in small groups serves as a means for the teacher to advance a different mathematical discourse from the discourse in the regular class. The difference is expressed in a more focused discourse that invites ability to express the thoughts in a more confident, clear, and convincing manner. ${ }^{7}$ The problem that arises in the regular learning environment in the individualized hour is the short time of the lesson (45 minutes), and the encounters that are held infrequently (once a week). Therefore, the suggestion is to hold one lesson frontally and another two online lessons in order to preserve a communicational continuum with the learner.

This article discusses the mathematical discourse that is held in small groups and in an online collaborative environment, with reference to two directions of action. The first direction is characteristics of mathematical discourse in an online collaborative environment, while the second is the relationship between the characteristics of the mathematical discourse held in small groups in an online environment and the development of the ability of reasoning among students with difficulties.

${ }^{2}$ Ministry of Education, Opportunities in Teaching and Learning in a Small Group. Department of Elementary Education, Pedagogical Administration, Ministry of Education, State of Israel, 2009. (Hebrew)

${ }^{3}$ Ministry of Education, Integrated Instruments: Guide to Work in the Individualized Hour, Department of Secondary Education, Pedagogical Administration, Ministry of Education, State of Israel, 2009. http://meyda.education.gov.il/files/ChinuchMukar/4.pdf [date of access: 1.07.2020]. (Hebrew)

${ }^{4}$ H. Gardner, Multiple Intelligences: Theory and Practice, Israel, 1996. (Hebrew); M.B. Imbeau, C.A. Tomlinson, Leading and Managing a Differentiated Classroom, Alexandria, VA 2010.

${ }^{5}$ M. Buzu-Shwartz, Y. Banya, Learning in Small Groups: Learning to Talk and Talking to Learn, Echo of Education, 2013 August, 88(07), p. 120-121. (Hebrew)

${ }^{6}$ National Council of Teachers of Mathematics (NCTM), Executive Summary Principles and Standards for School Mathematics, 2000, https:// www.nctm.org/uploadedFiles/Standards_and_ Positions/PSSM_ExecutiveSummary.pdf [date of access: 1.07.2020]; K. Stacey, What Is Mathematical Thinking and Why Is It Important?

${ }^{7}$ J. Katz, Developing Mathematical Thinking: A Guide to Rethinking the Mathematics Classroom, Rowman \& Littlefield Publishers, Lanham, Maryland 2014; National Council of Teachers of Mathematics (NCTM). 


\section{Collaborative Discourse in Small Groups}

Collaborative learning is a pedagogical approach that places the learner at the center, develops the cognitive structure, and increases the desire and motivation to learn. ${ }^{8}$ Cooperation among the learners is based on reciprocal dependence among them which consequently increases and promotes the learning process, ${ }^{9}$ for the achievement of a shared goal, such as the performance of a project and solving an assignment or problem. Learning in small groups is one of the methods of collaborative learning that constitutes collective learning in which every learner can contribute his part. ${ }^{10}$ In the process of collaborative learning, there is importance to the discourse developing among the learners themselves and between the learners and the teacher. The work between the teachers and the students and among the students themselves is reciprocal and encourages listening and the raising and sharing of ideas. ${ }^{11}$ McDonnell, Mathot-Buckner, Thorson, and Fister ${ }^{12}$ maintained that peer tutoring improves the academic response for students with difficulties.

According to the constructivist approach, the learning of mathematics is a social activity. In other words, learning occurs during the development of a dialogue between peers and the exchange of opinions between the community of learners who are involved in the building of mathematical knowledge through activity, discourse, and shared thinking. ${ }^{13}$

\section{Mathematical Discourse in Online Collaborative Learning as Mediating the Reasoning Ability among Students}

Teaching in a small group invites the use of learning environments based on technological means, which broaden the learner's sources of information

8 A.M. O'Donnell, J. Kelly, Learning from Peers: Beyond the Rhetoric of Positive Results, Educational Psychology Review, 1994, 6, p. 321-349.

${ }_{9}$ C.M. Brody, N. Davidson, Professional Development for Cooperative Learning: Issues and Approaches, New York 1998; Horizon Report, Higher Education Edition. 2017

${ }^{10}$ E.G. Cohen, Restructuring the Classroom: Conditions for Productive Small Groups, Review of Educational Research, 1994, 64(1), p. 1-35.

${ }^{11}$ M.P. Boyd, W.C. Markarian, Dialogic Teaching: Talk in Service of a Dialogic Stance, Language \& Education: An International Journal, 2011, 25(6), p. 515-534; M.R. Rawding, T. Wills, Discourse: Simple Moves that Work, Mathematics Teaching in the Middle School, 2012, 18(1), p. 46-51.

${ }^{12} \mathrm{~J}$. McDonnell et al., Supporting the Inclusion of Students with Moderate and Severe Disabilities in Junior High School General Education Classes: The Effects of Classwide Peer Tutoring, Multi-Element Curriculum, and Accommodations, Education and Treatment of Children, 2001 May, 24(2), p. 141160, https://www.jstor.org/stable/42899651 [date of access: 1.07.2020].

${ }_{13}$ R. Mintz, R. Nachmias, Teaching Science and Technology in the Era of Knowledge, Computers in Education, 1998, 45-46. (Hebrew); M. Tam, Constructivism, Instructional Design, and Technology: Implications for Transforming Distance Learning, Educational Technology and Society, 2000, 3(2); L.S. Vygotsky, Mind in Society: The Development of Higher Mental Process, Cambridge 1978; R. Zevenbergen, S. Dole, R. Wright, Teaching Mathematics in Primary Schools, Australia 2004. 
in the process of his learning and challenges the teacher to use diverse means of illustration in her teaching. ${ }^{14}$ Communication in this environment obligates the development of discourse abilities among students to increase the communication with one another so as to raise and to promote ideas that will serve as scaffolding and to create an effective class in which there is an authentic discourse. ${ }^{15}$ The concept of discourse addresses the system of relations and norms of behavior that is broader than those of conversation. This focuses the learners' thinking, promotes ideas, and reasoning ability that include mathematical arguments and rationales. ${ }^{16}$ The discourse in collaborative online learning environments is prominent in three circles: the social circle of the learner, the academic circle of the learner, and the instructional circle of the teachers.

The learner's social circle. Learning is a result of negotiations between people in order to product meaning. Technological instruments support meaningful discourse between the learners and advance collaborative building of knowledge and ideas. ${ }^{17}$ The social reciprocal relations that develop and the social mediation are two basic elements in the development of the high mental functions such as perception, attention, memory, thinking. ${ }^{18}$ This increases the students' participation in the lessons and the learning hours invested in the learning, and improves the group dynamics and cooperation, ${ }^{19}$ improves the learning experience, ${ }^{20}$ when the sharing and communication do not depend on time or place. ${ }^{21}$

The learner's academic circle. Technology offers the learners control of the learning processes and maximum of transference of knowledge. ${ }^{22}$ Pap-

${ }^{14}$ Ministry of Education, Integrated Instruments: Guide to Work in the Individualized Hour.

${ }^{15}$ M.R. Rawding, T. Wills, Discourse: Simple Moves, p. 46-51.

${ }^{16}$ National Council of Teachers of Mathematics (NCTM); H. Regev, S. Shimoni, The Mathematical Discourse One or More Discourse? Pamphlet for the Teacher of Mathematics, 2005, 34, p. 35-43. (Hebrew).

17 D.H. Jonassen, C. Chad, Y Hsiu-Ping, Computers as mindtools for engaging learners in critical thinking, TechTrends, 1998, 43, p. 24-32.

${ }_{18}$ G. Ilam, The Philosophy and Psychology of Vygotsky: From Cultural Instruments to Psychological Instruments, [in:] Lev Vygotsky - Thought and Culture, Eds. A. Kozulin, G. Ilam, Jerusalem 2003, p. 364-373. (Hebrew); G. Salomon, Communication: Concepts in the Educational Discussion, Sifriat Poalim, 1981. (Hebrew)

${ }^{19}$ K.R. Heggart, J. Yoo, Getting the Most from Google Classroom: A Pedagogical Framework for Tertiary Educators, Australian Journal of Teacher Education, 2018, 43(3), p. 140-153.

20 P.S. Hsu, Examining Current Beliefs, Practices and Barriers about Technology Integration: A Case Study, TechTrends: Linking Research and Practice to Improve Learning, 2016, 60(1), p. 30-40.

${ }^{21}$ Horizon Report, Higher Education Edition, 2017.

${ }_{22}$ C.H. Chen, V. Law, Scaffolding Individual and Collaborative Game-Based Learning in Learning Performance and Intrinsic Motivation, Computers in Human Behavior, 2016 February 55, p. 12011212. 
pert $^{23}$ emphasizes the importance of the visual-motor experience of the student with objects learned in the external reality. He maintains that children build their knowledge structures as a result of concrete experiences. The constructivist collaborative character in online learning environments increases in the learners their active participation in the learning process and enables the learners to build knowledge in the team, and to support in-depth reflective thinking necessary to meaningful learning. ${ }^{24}$ This process supports and improves the learning strategies and the coping with the memory problems. ${ }^{25}$ Difficulties in active memory and long-term memory influence the students' ability to solve problems and to examine thinking processes. ${ }^{26}$ The removal of the mental load, such as complicated calculations through the use of technology, and the 'offloading' of the mental burden from the person to the instrument encourage the performance of higher thinking processes. ${ }^{27}$ According to Chen and Law, ${ }^{28}$ learning in an online collaborative environment builds in-depth processes of learning and processing and greatly influences the transmission of knowledge and learning processes. Learning in an online collaborative emphasizes the learner's personal pace, through feedback and peer support. ${ }^{29}$

The teachers' instructional circle. In teaching in the small group, the teacher can advance every student in the group in a personal manner and the group in general through mediation and beneficial feedback that is immediate, detailed, provides information, is focused, and is given in a positive manner. ${ }^{30}$ The discourse that develops through the teacher's instruction develops the students' communicational ability and they share ideas with

${ }^{23}$ S. Papert, Introduction: Computers for Children; Computers and Computers Cultures, [in:] Mind-Storms. Children, Computers, and Powerful Ideas, Ed. S. Papert, New York 1980.

${ }^{24}$ R. Rimor, Decentralized Learning: From the Search for Information to the Construction of Knowledge - Processes of Organization and Construction of Knowledge in Computerized Environments of Databases, Negev 2002. (Hebrew); S. Rutherford, Collaborative Learning: Theory, Strategies, and Educational Benefits, New York 2014; G. Salomon, Technology and Education in the Information Era, Tel Aviv 2000. (Hebrew)

${ }^{25}$ A. Drigas, G. Kokkalia, M.D. Lytras, ICT and Collaborative Co-Learning in Preschool Children Who Face Memory Difficulties, Computers in Human Behavior, 2015 October, 51, p. 645-651.

${ }^{26}$ D.C. Geary, Mathematics and Learning Disabilities, Journal of Learning Disabilities, 2004, 37, p. 4-15.

${ }^{27}$ G. Salomon, Communication; Technology and Education.

${ }_{28}$ C.H. Chen, V. Law, Scaffolding Individual, p. 1201-1212.

${ }^{29}$ M. Dunleavy, S. Dexter, W. Heinecke, What Added Value Does a 1:1 Student to Laptop Ratio Bring to Technology-Supported Teaching and Learning? Journal of Computer Assisted Learning, 2007, 23, p. 440-452.

${ }^{30}$ N. Hativa, Teaching Processes in the Classroom, Tel Aviv 2003. (Hebrew) 
other learners, through enjoyment in the process. ${ }^{31}$ Weiss $^{32}$ holds that the combination between a smart teacher and smart technology produces successful classes. Online environments enable the teacher:

- To adopt approaches of collaborative instruction that will suit the learning needs of the different learners and thus dedicate more time to work individually. ${ }^{33}$

- To improve the teachers' teaching through the use of diverse technological means that help reduce learning gaps and increase motivation. ${ }^{34}$

\section{Students with Mathematics Learning Difficulties in Middle School - Problems and Challenges}

According to the sociocultural approach, students who have difficulties in mathematics are students whose learning achievements are low, ${ }^{35}$ and consequently they developed experience of frustration, feeling of failure, lack of motivation, ${ }^{36}$ and lack of self-confidence to participate in mathematical activities. ${ }^{37}$

There is a distinction between two different characteristics of students with difficulties: environmental characteristics and learner characteristics. Environmental characteristics refer to students who did not succeed in acquiring learning skills because of environmental factors related to the nature of the teacher's guidance, style of teaching, and curriculum load.$^{38}$ In addition, the misleading use of mathematical language and means of illustration and rigid requirements of the learner such as the demand to memorize without the internalization of meaning, rapid pace of learning, and lack of reference

\footnotetext{
${ }^{31}$ M.R. Rawding, T. Wills, Discourse: Simple Moves, p. 46-51.

${ }^{32}$ D. Weiss, Pedagogical Sympathy to Technological Instruments, Echo of Education Journal, 2010, p. 80-82. (Hebrew)

${ }_{33}$ Horizon Report, Higher Education Edition. 2017.

${ }^{34}$ P. Stanford, M.W. Crowe, F. Hollie, Differentiating with Technology, Teaching Exceptional Children Plus, 2010 April, 6(4).

${ }^{35}$ B. Denvir, C. Stolz, M. Brown, Low Attainers in Mathematics, Policies and Practices in Schools, London 1982, p. 5-16.

${ }^{36}$ T. Ben Yehuda, P. Licht, Implementation of a Model for Tailored Intervention: Teaching Groups of Learners with Difficulties in Mathematics Who Are Integrated in Regular Education, [in:] Inclusion: Learners with Disabilities in the Education System, Eds. G. Avisar, S. Reiter, Haifa 2013; D.C. Geary, The Origin of Mind: Evolution of Brain, Cognition, and General Intelligence, Washington 2005, http:/ / dx.doi.org/10.1037/10871-000; S.R. Goldman, Strategy Instruction in Mathematics, Learning Disabilities Quarterly, 1989, 12, p. 43-55.

${ }^{37}$ D. Haylock, Teaching Mathematics to Low Attainers, London 1991, p. 8-12.

${ }_{38}$ T. Ben Yehuda, P. Licht, Implementation of a Model for Tailored Intervention.
} 
to the cognitive differences among the learners causes the accumulation of gaps in mathematics among the students and makes it difficult for the learners in the continuation. ${ }^{39}$ The learner's characteristics include: the slow or inaccurate retrieval of basic arithmetic facts, understanding of number, number operations, and relationship, number estimation, counting knowledge, and arithmetic, ${ }^{40}$ the problem of the creation and preservation of mental images of mathematical, ${ }^{41}$ difficulties in active memory such as understanding the concept of the number and understanding basic arithmetic facts and solving problems that require for solution a number of steps, and long-term memory of contents: memory of facts and memory of procedures. ${ }^{42}$

One of the main challenges today in the teaching of mathematics to students with difficulties is to involve them actively in the building of their mathematical knowledge from understanding and to avoid routine learning of procedures. ${ }^{43}$ In the present research study, the students' involvement was undertaken through the development of an online mathematical discourse, built in a learning environment that suits the group in order to challenge them and to give them an opportunity to develop the mathematical thinking through the development of the reasoning ability in the problem solving process. In the research study the characteristics of the use of the online collaborative environment were examined, with emphasis on the creation of a discourse as promoting the ability to reason among students with difficulties.

\section{Research Questions}

1. What are the characteristics of mathematical discourse occurring in an online environment in small groups of students who have difficulties?

2. What is the connection between the characteristics of mathematical discourse occurring in an online environment and the reasoning ability of students who have difficulties?

The present research questions constitute a part of the comprehensive research study carried out as a part of my doctoral research study. This research

${ }^{39}$ R. Kidron, Difficulties in Learning Arithmetic, Tel Aviv 1985. (Hebrew)

${ }^{40}$ N.C. Jordan, S.C. Levine, Socio-Economic Variation, Number Competence, and Mathematics Learning Difficulties in Young Children, Developmental Disabilities Research Reviews, 2009, 15; D.C. Geary et al., Cognitive Mechanisms Underlying Achievement Deficits in Children with Mathematical Learning Disability, Child Development, 2007, 78. of Brain.

${ }^{41}$ D.C. Geary, Mathematics and Learning Disabilities, p. 4-15; The Origin of Mind: Evolution

${ }^{42}$ Ibidem, p. 4-15.

${ }^{43}$ D. Haylock, Teaching Mathematics to Low Attainers, p. 8-12. 
study will help provide an outline and helped me as a researcher about the building of the questions and the hypotheses and the organization of the activities in the comprehensive research.

\section{Case Study Research Process}

The research study is a case study, which focuses on one case that has the scope of a closed system and observes the characteristics of the researched case ${ }^{44}$ According to Stake, ${ }^{45}$ this is an intrinsic case study, in which the researcher describes in-depth the details of the case through the investigation of a single person. ${ }^{46}$ If so, in our case this is the teacher of the group of learners who were chosen to undergo the process.

In the framework of the research study, the teacher conducted ten frontal mathematics lessons (every week a lesson). Every lesson is about an individualized frontal hour (45 minutes), and during the week three online lessons were performed (about 40 minutes every lesson). The teacher communicated with the students through the use of synchronous online environments called "Mashov". ${ }^{47}$ The lessons were held in a group of five students who learn in the eighth grade in a middle school in the state education sector. The students are students who have difficulties in mathematics. The teachers in the school mathematics staff selected the students. The choice of the students was carried out from the category of students who receive in the annual mapping tests a score of 50-60.

The research study lasted about three months after the annual mapping test, which was held in October of the 2019-2020 school year. The assignments are complex tasks built on phrasing answers, justification, and drawing conclusions. ${ }^{48}$ The assignments were defined as authentic, challenging, and executable.

${ }^{44}$ Y. Friedman, Measurement and Assessment of Social and Educational Programs, Henrietta Szold Institute, 2005. (Hebrew)

${ }^{45}$ R.E. Stake, Case studies, [in:] Handbook of Qualitative Research ( $2^{\text {nd }}$ Ed.), Eds. N.K. Denzin, S.L. Lincoln, London 2000.

${ }^{46}$ Y. Friedman, Measurement and Assessment.

${ }^{47}$ MASHOV is a Hebrew acronym for Immediacy, Transparency, and Control. The word means feedback. MASHOV is an Internet-based pedagogical management system used by schools in the education system in Israel. The software was developed in the year 2006. The use of the software by the school staff, the student, and the parents contributes to transparency in the ongoing updates, the improvement of the relationship between the school staff and the student and the parents, and the improvement of the effectiveness in the everyday work in the staffs themselves.

${ }^{48}$ Ministry of Education, Director General Circular 1995: Tests and Assessment in the Elementary School: National Feedback and School Feedback, 1996. (Hebrew) 


\section{Characteristics of Mathematical Discourse in an Online Collaborative Environment - Analysis of Research Data}

The analysis was carried out in two stages. The first stage was the identification of the characteristics of the mathematical discourse that develops among the students themselves and between the students who have difficulties and the teacher in the online environment. For this purpose, all the recordings of the mathematical discourse held in the online environment were collected. The second stage examined the connection between the characteristics of the mathematical discourse held in the online collaborative environment in a small group on the advancement of the reasoning ability of the learner who has difficulties. In addition, an interview was held with the mathematics teacher who performed the process.

\section{Characteristics of the Mathematical Discourse in an Online Collaborative Environment}

The analysis of the data on the conversation held between the learners and their peers and between the learners and the teacher indicates five characteristics of mathematical discourse related to the qualities of the use of the online collaborative environment among students with difficulties:

1. Mediating mathematical discourse. Mathematical discourse has four characteristics: ${ }^{49}$ words and manner of use of the words, visual mediators, routines, and agreed-upon statements. Students with difficulties have limited ability to remember and difficulty in the conceptualization ability. The online environment enabled the building of an accessible index for the concepts necessary for the tasks, the means of illustration, figures, navigation cards, and concentration of concepts that helps in recall and immediate retrieval. The accessibility was performed with emphasis on the agreed-upon concepts and statements required as a hyperlink that includes explanation and example of use. The means of illustration and the visual representations are essential in the teaching of mathematics since they bridge between the abstract idea and its representation and the concrete tangible level, ${ }^{50}$ thus

49 A. Sfard, I. Lavie, Objects from Talk: How Small Children Create Numbers in Conversation, Research and Study in Mathematical Education, 2016 November, 4, p. 22-68. (Hebrew)

${ }^{50}$ L. Linchevsky, H. Tuval, The Role of the Models as an Auxiliary Means for Those with Difficulties in Arithmetic: Analysis of the Concept of the Fraction, Trends, 1993, 35, p. 96-109. (Hebrew) 
improving the ability of memory and understanding and increasing the effectiveness of the learning process. ${ }^{51}$

2. Discourse in an online environment creates a communicational cognitive continuum. Students with learning difficulties need mediated learning with continuum and organization on the level of thinking. Sfard ${ }^{52}$ and Sfard and Lavie ${ }^{53}$ proposed the term "commognition", which unites communication theories and cognition theories, when the basis of the unification is from the fundamental assumption that thinking is a process of self-communication, the person's communication with himself and therefore thinking and communication are two parts that build the phenomenon. This is the ability for the appropriate acquisition of the verbal ability, symbols, and development of expression ability, through verbal and also visual practice in the online environment. In addition, in an online collaborative environment the learner is at the center. The building of the interpersonal communicational ability is more associated with the process of teaching, a process that is important because it encourages the discourse and its development among the learners. ${ }^{54}$ The development of the discourse creates an environment that promotes the sharing of ideas and ability to explain without fear of mistakes, when the teacher serves as an instructor. The lack of judgment in the communication between the learners creates an atmosphere of confidence, encouragement, and support.

3. Discourse that promotes assessment and location of the mathematical discourse in an online environment serves the teacher as a tool for the assessment and location of the learner's difficulties (weak points), while assessing the source of the difficulty, whether this derives from the understanding of the material or from the process of the solution and accordingly tailoring a personal learning program for the student with difficulty. Wagganer ${ }^{55}$ emphasizes the differentiation in the mathematical discourse between explanation and justification, when explanation is the description of the process through which they reach the solution and proof of why we solved in this way. According to Regev and Shimoni, ${ }^{56}$ this is a meta-cognitive discourse, "thinking about mathematical thinking". The discourse with the learners is related to the process of solving (and not only a numerical process), a discourse about

${ }^{51}$ R.E. Mayer (Ed.), The Cambridge Handbook of Multimedia Learning, New York 2005; R.E. Mayer, Multimedia Learning, New York 2009.

${ }^{52}$ A. Sfard, Thinking as Communicating: Human Development, Development of Discourses, and Mathematizing.: Cambridge University Press, New York 2008.

53 A. Sfard, I. Lavie, Objects from Talk, p. 22-68. (Hebrew)

${ }^{54}$ M.H. Pace, E. Ortiz, Get the GOOF!, Teaching Children Mathematics, 2016, 23(3), p. 138-144.

55 E.L. Wagganer, Creating Math Talk Communities, Teaching Children Mathematics, 2015, 22(4), p. 248-254.

${ }^{56}$ H. Regev, S. Shimoni, The Mathematical Discourse, p. 35-43. 
the mistakes, the type of mistakes, and the process of solving. ${ }^{57}$ The discourse is undertaken in two dimensions: the intrapersonal dimension in which the learner examines the personal knowledge he acquired during his learning, as opposed to the interpersonal dimension - in the group discourse, when in the group dynamics the learner is more confident to explain in greater depth the mathematical strategies they used to solve the tasks. ${ }^{58}$ The discourse in the online environment creates in-depth learning on the nature of the learner's thinking in a documented manner, the follow-up of the discourse after the obstacles, and the learner's lack of understandings of the material offer a challenge to close content gaps during the continuation in the material.

4. Differential personal mathematical discourse in an online environment. Differential personal discourse that shapes and mediates is necessary to promote the students who have difficulties so as to close the learner's special content gaps. Following the identification of the learner's specific difficulty, the teacher develops an individualized discourse that has the goal of advancing and challenging the learner so as to continue and to preserve the learner's academic place in the group. Learning is effective and is performed when we know the learner's current level of development and the place from which he will begin to grow towards higher levels through giving assignments appropriate to his abilities, in ways of teaching suited to the learner's preferences since the teaching is performed in the zone of proximal development. ${ }^{59}$ This tailoring motivates the learners and creates for them experiential and challenging learning that suits their style of learning. ${ }^{60}$ The goal of the differential level of discourse and the follow up of this content is to maximize the success of every learner through the performance of a thinking process focused on the individual, with the adjustment of the content, the process, and the product. ${ }^{61}$

5 . The mathematical discourse in the group as a basis for formative assessment in the online environment. Weiss ${ }^{62}$ maintains that the combination of a smart teacher and smart technology produces successful classes. Teaching in an online environment, which makes use of the database of interactive digital contents, will provide a differential response to the learners' range of

\footnotetext{
${ }^{57}$ Ministry of Education, Culture, and Sport, Collection of Assignments in Mathematics for School Assessment, The Center for Educational Technology, 1995. (Hebrew)

${ }^{58}$ E. Wenger-Trayner, B. Wenger-Trayner, Introduction to Communities of Practice, 2015, https://wenger-trayner.com/introduction-to-communities-of-practice/Google Scholar [date of access: 1.07.2020].

${ }^{59}$ L.S. Vygotsky, Mind in Society.

${ }^{60} \mathrm{H}$. Gardner, Multiple Intelligences.

${ }^{61}$ C.A. Tomlinson, The Differentiated Classroom: Responding to the Needs of All Learners, New
} York 2005.

${ }^{62}$ D. Weiss, Pedagogical Sympathy, p. 80-82. (Hebrew) 
abilities and needs and will help the teacher support the learners in diverse situations of learning through feedback in real-time about the students' performances. This is continuous formative assessment throughout the discourse and immediately, which enables adjusted planning of the continuations of the learning processes. The giving of constant formative assessment to the learners that is accompanied by support and instruction, by the identification of unique needs, by the monitoring of the learner in real-time, and by the work in flexible groups suited to their learning style and to their manner of progress increase the motivation to learn. ${ }^{63}$

\section{Mathematical Meta-Cognitive Online Discourse and Its Meaning for the Student with Difficulties}

The mathematical meta-cognitive discourse that is built in an online environment created a communicational continuum in the learner himself and between the learner and the group. The analysis of the connection between the characteristics of the mathematical discourse and the development of reasoning ability was carried out while examining the development of abilities in the learner who has difficulties and the abilities required of the student on the

\begin{tabular}{|c|c|}
\hline Abilities Examined & Advanced / Inhibited / No change \\
\hline Mathematical reasoning & + \\
\hline Mathematical communication & + \\
\hline Ability to present and solve problems & + \\
\hline Representations & + \\
\hline Connections & + \\
\hline Mathematical aids and tools \\
competency & the change in the non-formal and concert \\
level
\end{tabular}

${ }^{63}$ M. Dunleavy, S. Dexter, W. Heinecke, What Added Value Does a 1:1 Student, p. 440-452; J. Keshet-Meor, Differential Teaching in the 21 ${ }^{\text {st }}$ Century, [in:] Equals: School Support of Equality of Opportunity, Ed. J. Mandel-Levy, Jerusalem 2017, p. 7-12. (Hebrew); C.A. Tomlinson, How to Differentiate Instruction in Mixed-Ability Classrooms, Alexandria 1995. 
basis of the article of Niss. ${ }^{64}$ This article describes the requirements accepted in the OECD countries that examine the learner's understanding and academic development.

Mathematical reasoning is defined as the process of reaching a decision by using critical, creative, and logical thinking. ${ }^{65}$ For this ability, the mathematical discourse among peers helped the learner develop analytical thinking and meta-cognitive skills important to the development of their mathematical thinking ability. ${ }^{66}$ The mathematical communication created between the learners brought up new ideas and created an opportunity to focus their thinking. For instance, when presenting problems so as to solve them, the learner appears more certain to express his emotions when every learner gave some of his personal knowledge. The communication became clearer using the discourse that the teacher developed with the learners. The teacher's corrections and mediations brought the discourse up a level, and the learners attempted to explain their arguments while using mathematical language and taking care to be clear and convincing. ${ }^{67}$

The mathematics teacher reported: "The students participated more in the online lesson, at first they would toss out answers to the tasks in which they participated randomly and sometimes they only wanted to be the first to solve, when I began to ask them to explain their answers and to address the process of solving they withdrew from participating, but the encouragement and participation with the friends and the giving of help in the development of the ideas for the solution they gave advanced them greatly. Every week we would do very similar tasks so as to assimilate what was learned and to keep the discourse with the same concepts."

The use of the visual and tangible technological aids helped the learner to connect between the mathematical ideas in a more meaningful and interesting manner ${ }^{68}$ and to remember learning materials through the use of a hyperlink that the teacher prepared ahead of time for review and recall. The hyperlink served as the navigation ticket for the learner to bypass the problem of memory and to improve his ability to organize through giving examples of the manner of use of the concepts. This solved the problem of recall and organization, which are characteristic of the learner with difficulty.

${ }^{64}$ M. Niss, Mathematical Competence and PISA, [in:] Assessing Mathematical Literacy: The PISA Experience, The Foundations of PISA Mathematics, Eds. K. Stacey, R. Turner, Switzerland 2015, p. 35-55.

65 E. Erdem, R. Gürbüz, An Analysis of Seventh-Grade Students' Mathematical Reasoning, Cukurova University Faculty of Education Journal, 2015, 44, p. 123-142.

${ }^{66}$ J. Katz, Developing Mathematical Thinking.

67 Ibidem; National Council of Teachers of Mathematics (NCTM).

${ }^{68}$ National Council of Teachers of Mathematics (NCTM); M. Niss, Mathematical Competence and PISA, p. 35-55. 
The teacher said, "The use of the online environment enables us as teachers to build an index - a dictionary of concepts that enables the student to use it when needed. For every concept encountered we made with a hyperlink a card that explained about the concept and the uses, including examples."

It is necessary to visually process the given problem and to perform the calculation steps before reach a decision and selecting the appropriate response. ${ }^{69}$

"The use of the mathematics software programs and applications enable the students to move the graphs and the shapes, which helps them, of course according to the questions, to understand or to draw conclusions about the dependence of factors in the question, such as area, perimeter, and volume and their relationship to the length of a certain side."

Mathematical symbols and formalism. In the beginning of the process, the translation from spoken and regular language to mathematical language was difficult for the learners. The learners had difficulties with the use of statements and expressions that include symbols and formulae, the use of variables, solving equations, and performing arithmetic actions in the correct way. This influenced the ability to build mathematical modeling. The learners had difficulties analyzing correctly the mathematical model of the problem, and accordingly it was hard for them to critique their work and the results as a part of the process of solving mathematical problems. In this part, the teacher's mediation and involvement in the discourse provided scaffolding for the learners and upped the level of thinking. The learners succeed in providing arguments and drawing conclusions on a non-formal and concrete level. This ability of providing an explanation is a part of the drawing of conclusions and solving of problems. ${ }^{70}$ The progress in both abilities was negligible, but there is still an improvement.

According to the teacher, "To build this ability more time is needed, it is necessary to remember that it is impossible to bridge many gaps in such a short period of time. This requires much work and much support of the learners in the process of the internalization."

\section{Conclusion}

This article emphasizes the importance of the individualized hour as part of the process for the advancement of learners who have difficulties in

\footnotetext{
${ }^{69}$ M.J. Vansteensel et al., Spatiotemporal Characteristics of Electrocortical Brain Activity during Mental Calculation, Human Brain Mapping, 2014, 35(12), p. 5903-5920.

70 OECD, PISA 2021 Mathematics Framework (Draft) - November 2018; https://pisa2021-maths.oecd.org/files/PISA\%202021\%20Mathematics\%20Framework\%20Draft.pdf [date of access: 1.07.2020].
} 
mathematics. The effectiveness of the individualized hour increases when it is used in an online learning environment, which encourages the learner to more effective learning when the communicational continuum between the learner and the material and between the learner and the group is preserved. The teacher serves as an instructor and supports the learning process, provides formative feedback immediately, and enables appropriate mediation for the learner who has difficulties personally. The learning process that includes authentic mathematical tasks pushes and encourages the development of mathematical thinking abilities among the learners with difficulties. The development of thinking was undertaken through the promotion of a mathematical discourse that includes the bringing up of arguments, the drawing of conclusions, and the ability to verbalize their thinking, to raise hypotheses or arguments, and to know to explain/justify these arguments. ${ }^{71}$

In an interview that was held with the teacher, she reported about the improvement:

"I see an improvement in the students' participation in the preparation of homework, participation in the lessons and raising the hand, and correct use of mathematical language and symbols, and naming of concepts, the children began to explain their answers and to explain ore their attitudes and their manner of thinking"

This is the ability of the learners to create communication between them, while asking questions and developing an argument through which it is possible to explain their thinking. ${ }^{72}$ Mathematical discourse encourages students to examine and to monitor the form and processes of their thinking and increases their belief in themselves regarding problem solving. ${ }^{73}$

In feedback that the teacher did with the students at the end of the process a number of recurring statements were observed.

I enjoy learning in a group, there we are a few and the teacher answers all my questions, sometimes I do not understand, she gives me explanations." "I do not always participate, and

${ }^{71}$ Common Core State Standards Initiative, Common Core State Standards for Mathematics (CCSSM). Washington, DC: The National Governors Association Center for Best Practices and Council of Chief State School Officers, 2010. http://www.corestandards.org/wp-content/ uploads/Math_Standards1.pdf [date of access: 1.07.2020]; A. Schoenfeld, Learning to Think Mathematically: Problem Solving, Metacognition, and Sense-Making in Mathematics, Journal of Education, 2016, 196(2), p. 1-38.

72 S.S. Yagi, An Exploration of First Grade Students' Engagement in Mathematical Processes during Whole Group Discussions, [in:] Proceedings of the 38th annual meeting of the North American Chapter of the International Group for the Psychology of Mathematics Education, Eds. M.B. Wood, E.E. Turner, M. Civil, J.A. Eli, Tucson 2016, p. 688-691.

${ }^{73}$ L.B. Cooke, V.M. Adams, Encouraging "Math Talk" in the Classroom, Middle School Journal, 1998, 29(5), p. 35-40; M.L. Franke et al., Student Engagement with Others' Mathematical Ideas: The Role of Teacher Education and Support Moves, The Elementary School Journal, 2015, 116, p. 126-148. 
the teacher does not let me alone; she communicates with me and asks me to participate and is encouraging." "It is fun for me to learn through the computer, there are always new things and sometimes when I forget I do not need a pen and a paper, everything in the conversation is written, it is possible to repeat things."

The management of a conversation or discussion enables learning that is "collective, reciprocal, supportive, cumulative, and purposeful."74

\section{BIBLIOGRAPHY}

Ben-Yehuda T., Licht P., Implementation of a Model for Tailored Intervention: Teaching Groups of Learners with Difficulties in Mathematics Who Are Integrated in Regular Education, [in:] Inclusion: Learners with Disabilities in the Education System, Eds. G. Avisar, S. Reiter, Achva Press, Haifa 2013. (Hebrew)

Boyd M.P., Markarian W.C., Dialogic Teaching: Talk in Service of a Dialogic Stance, Language \& Education: An International Journal, 2011, 25(6).

Brody C.M., Davidson N., Professional Development for Cooperative Learning: Issues and Approaches, State University of New York Press Albany, New York 1998.

Buzu-Shwartz M., Banya Y., Learning in Small Groups: Learning to Talk and Talking to Learn, Echo of Education, 2013 August, 88(07). (Hebrew)

Chen C.H., Law V., Scaffolding Individual and Collaborative Game-Based Learning in Learning Performance and Intrinsic Motivation, Computers in Human Behavior, 2016 February, 55.

Cohen E.G., Restructuring the Classroom: Conditions for Productive Small Groups, Review of Educational Research, 1994, 64(1).

Common Core State Standards Initiative, Common Core State Standards for Mathematics (CCSSM). Washington DC: The National Governors Association Center for Best Practices and Council of Chief State School Officers. http://www.corestandards.org/wpcontent/uploads/Math_Standards1.pdf [1.07.2020].

Cooke L.B., Adams V.M., Encouraging "Math Talk" in the Classroom, Middle School Journal, 1998, 29(5).

Denvir B., Stolz C., Brown M., Low Attainers in Mathematics, Policies and Practices in Schools, Schools Council Working Paper, 1982, 72, 5-16, Methuen Educational, London.

Drigas A., Kokkalia G., Lytras M.D., ICT and Collaborative Co-Learning in Preschool Children Who Face Memory Difficulties, Computers in Human Behavior, 2015 October, 51.

Dunleavy M., Dexter S., Heinecke W., What Added Value Does a 1:1 Student to Laptop Ratio Bring to Technology-Supported Teaching and Learning? Journal of Computer Assisted Learning, 2007, 23.

Erdem, E., Gürbüz R., An Analysis of Seventh-Grade Students' Mathematical Reasoning, Cukurova University Faculty of Education Journal, 2015, 44.

Franke M.L., Turrou A.C., Webb N.M., Ing M., Wong J., Shin N., Fernandez C., Student Engagement with Others' Mathematical Ideas: The Role of Teacher Education and Support Moves, The Elementary School Journal, 2015, 116.

Friedman Y., Measurement and Assessment of Social and Educational Programs, Henrietta Szold Institute 2005. (Hebrew)

${ }^{74}$ M.P. Boyd, W.C. Markarian, Dialogic Teaching, p. 529. 
Gardner H., Multiple Intelligences: Theory and Practice, Branco Weiss Institute for the Cultivation of Thinking \& Department of Curricula, Ministry of Education, Culture, \& Sport, Israel 1996. (Hebrew)

Geary D.C., Mathematics and Learning Disabilities, Journal of Learning Disabilities, 2004, 37.

Geary D.C. The Origin of Mind: Evolution of Brain, Cognition, and General Intelligence, American Psychological Association, Washington DC, US 2005 http://dx.doi. org/10.1037/10871-000

Geary D.C., Hoard M.K., Byrd-Craven J. et al., Cognitive Mechanisms Underlying Achievement Deficits in Children with Mathematical Learning Disability, Child Development, 2007, 78.

Goldman S.R., Strategy Instruction in Mathematics, Learning Disabilities Quarterly, 1989, 12.

Hativa N., Teaching Processes in the Classroom, Academic Press for the Development of Teaching Faculty in the Classroom, Tel Aviv 2003. (Hebrew)

Haylock D., Teaching Mathematics to Low Attainers, Paul Chapman Publishing, London 1991.

Heggart K.R., Yoo J., Getting the Most from Google Classroom: A Pedagogical Framework for Tertiary Educators, Australian Journal of Teacher Education, 2018, 43(3).

Horizon Report, Higher Education Edition, 2017.

Hsu P.S., Examining Current Beliefs, Practices and Barriers about Technology Integration: A Case Study, TechTrends: Linking Research and Practice to Improve Learning, 2016, 60(1).

Ilam G., The Philosophy and Psychology of Vygotsky: From Cultural Instruments to Psychological Instruments, [in:] Lev Vygotsky - Thought and Culture, Eds. A. Kozulin, G. Ilam, Branco Weiss Institute, Jerusalem 2003. (Hebrew)

Imbeau M.B., Tomlinson C.A., Leading and Managing a Differentiated Classroom, ASCD, Alexandria, VA 2010.

Jonassen D.H., Chad C., Hsiu-Ping Y., Computers as mindtools for engaging learners in critical thinking, TechTrends, 1998, 43.

Jordan N.C., Levine S.C., Socio-Economic Variation, Number Competence, and Mathematics Learning Difficulties in Young Children, Developmental Disabilities Research Reviews, $2009,15$.

Katz J., Developing Mathematical Thinking: A Guide to Rethinking the Mathematics Classroom, Rowman \& Littlefield Publishers, Lanham, Maryland 2014.

Keshet-Meor J., Differential Teaching in the 21 ${ }^{\text {st }}$ Century, [in:] Equals: School Support of Equality of Opportunity, Ed. J. Mandel-Levy, Avney Rosha Institute, Jerusalem 2017. (Hebrew)

Kidron R., Difficulties in Learning Arithmetic, Otsar Hamore, Tel Aviv 1985. (Hebrew)

Linchevsky L., Tuval H., The Role of the Models as an Auxiliary Means for Those with Difficulties in Arithmetic: Analysis of the Concept of the Fraction, Trends, 1993, 35. (Hebrew)

Mason J., Burton L., Stacey K., Thinking Mathematically, Pearson Education Limited, Inggris 2010.

Mayer R.E. (Ed.), The Cambridge Handbook of Multimedia Learning, Cambridge University Press, New York 2005.

Mayer R.E., Multimedia Learning, Cambridge University Press, New York 2009.

McDonnell J., Mathot-Buckner C., Thorson N., Fister S., Supporting the Inclusion of Students with Moderate and Severe Disabilities in Junior High School General Education Classes: The Effects of Classwide Peer Tutoring, Multi-Element Curriculum, and Accommodations, Education and Treatment of Children, 2001 May, 24(2), https://www.jstor.org/stable/42899651 [date of access: 1.07.2020]

Ministry of Education, Director General Circular 1995: Tests and Assessment in the Elementary School: National Feedback and School Feedback, 1996. (Hebrew)

Ministry of Education, Integrated Instruments: Guide to Work in the Individualized Hour, Department of Secondary Education, Pedagogical Administration, Ministry of Educa- 
tion, State of Israel, 2009: http:/ / meyda.education.gov.il/files/ChinuchMukar/4.pdf [date of access: 1.07.2020]. (Hebrew)

Ministry of Education, Opportunities in Teaching and Learning in a Small Group, Department of Elementary Education, Pedagogical Administration, Ministry of Education, State of Israel, 2009. (Hebrew)

Mintz R., Nachmias R., Teaching Science and Technology in the Era of Knowledge, Computers in Education, 1998, (Hebrew)

National Council of Teachers of Mathematics (NCTM), Executive Summary Principles and Standards for School Mathematics, 2000. https://www.nctm.org/uploadedFiles/Standards_and_Positions/PSSM_ExecutiveSummary.pdf [date of access: 1.07.2020]

Niss M., Mathematical Competence and PISA, [in:] Assessing Mathematical Literacy: The PISA Experience, The Foundations of PISA Mathematics, Eds. K. Stacey, R. Turner, Springer International Publishing Switzerland 2015.

O'Donnell A.M., Kelly J., Learning from Peers: Beyond the Rhetoric of Positive Results, Educational Psychology Review, 1994, 6.

OECD (2018). PISA 2021 Mathematics Framework (Draft) - November. https://pisa2021-maths.oecd.org/files/PISA\%202021\%20Mathematics\%20Framework\%20Draft. pdf [date of access: 1.07.2020].

Pace M.H., Ortiz E., Get the GOOF! Teaching Children Mathematics, 2016, 23(3).

Papert S., Introduction: Computers for Children; Computers and Computers Cultures, [in:] Mind-Storms. Children, Computers, and Powerful Ideas, Ed. S. Papert, Basic Books Inc., New York 1980.

Rawding M.R., Wills T., Discourse: Simple Moves that Work, Mathematics Teaching in the Middle School, 2012, 18(1).

Regev H., Shimoni S., The Mathematical Discourse One or More Discourse? Pamphlet for the Teacher of Mathematics, 2005, 34. (Hebrew)

Rimor R., Decentralized Learning: From the Search for Information to the Construction of Knowledge - Processes of Organization and Construction of Knowledge in Computerized Environments of Databases, Ph.D. Dissertation, Ben Gurion University of the Negev 2002. (Hebrew)

Rutherford S., Collaborative Learning: Theory, Strategies, and Educational Benefits, Nova Science Publishers, Inc., New York 2014.

Salomon G., Communication: Concepts in the Educational Discussion, Sifriat Poalim 1981. (Hebrew)

Salomon G., Technology and Education in the Information Era, Haifa University - Zmora-Betan Press, Tel Aviv 2000. (Hebrew)

Schoenfeld A., Learning to Think Mathematically: Problem Solving, Metacognition, and Sense-Making in Mathematics, Journal of Education, 2016, 196(2).

Sfard A., Thinking as Communicating: Human Development, Development of Discourses, and Mathematizing, Cambridge University Press, New York 2008.

Sfard A., Lavie I., Objects from Talk: How Small Children Create Numbers in Conversation, Research and Study in Mathematical Education, 2016 November, 4. (Hebrew)

Stacey K., What Is Mathematical Thinking and Why Is It Important? Paper Presented in APEC Symposium: Innovative Teaching Mathematics through Lesson Study II, 2006 December, 3-4.

Stake R.E., Case studies, [in:] Handbook of Qualitative Research (2 ${ }^{\text {nd }}$ Ed.), Eds. N.K. Denzin, S.L. Lincoln, Sage Publications, London 2000.

Stanford P., Crowe M.W., Hollie F., Differentiating with Technology, Teaching Exceptional Children Plus, 2010 April, 6, 4. 
Tam M., Constructivism, Instructional Design, and Technology: Implications for Transforming Distance Learning, Educational Technology and Society, 2000, 3(2).

Tomlinson C.A., How to Differentiate Instruction in Mixed-Ability Classrooms, Association for Supervision and Curriculum Development, Alexandria VA 1995.

Tomlinson C.A., The Differentiated Classroom: Responding to the Needs of All Learners, Pearson, Upper Saddle River, New York 2005.

Vansteensel M.J., Bleichner M.G., Freudenburg Z.V., Hermes D., Aarnoutse E.J., Leijten F.S., ... Ramsey N.F., Spatiotemporal characteristics of electrocortical brain activity during mental calculation, Human Brain Mapping, 2014, 35(12).

Vygotsky L.S., Mind in Society: The Development of Higher Mental Process, Harvard University Press, Cambridge 1978.

Wagganer E.L., Creating Math Talk Communities, Teaching Children Mathematics, 2015, 22(4).

Weiss D., Pedagogical Sympathy to Technological Instruments, Echo of Education Journal, 2010. (Hebrew)

Wenger-Trayner E., Wenger-Trayner B., Introduction to Communities of Practice, 2015, https:/ / wenger-trayner.com/introduction-to-communities-of-practice/Google Scholar [date of access: 1.07.2020].

Yagi S.S., An Exploration of First Grade Students' Engagement in Mathematical Processes during Whole Group Discussions, [in:] Proceedings of the 38th annual meeting of the North American Chapter of the International Group for the Psychology of Mathematics Education, Eds. M.B. Wood, E.E. Turner, M. Civil, J.A. Eli, The University of Arizona, Tucson, AZ 2016.

Zevenbergen R., Dole S., Wright R., Teaching Mathematics in Primary Schools, Allen \& Unwin, Australia 2004. 